\title{
Developing Design Skills in Teaching 3D Modeling at the Pre-University Level
}

\author{
Lokalov, Vladimir Anatolievich; Klimov, Igor Viktorovich and Makhlai, Dmitrii \\ Olegovich \\ Department of Graphic Technologies, ITMO University, Russian Federation.
}

\begin{abstract}
The article highlights the importance of introducing students to design skills while teaching them 3D modeling at the pre-university level. Theoretical justification of the approach is offered; the approach uses a step-by-step differentiation of the orienting basis structure of the students' trainingrelated activities as the principal psychological model of the process of developing the design skills. Three stages of developing the professional skills are distinguished and described: elementary, basic and professional. Types of assignments for each stage are analyzed. A case study of using the approach in question for courses in $3 D$ modeling at Schoolchildren's Computer Center (SCC) of ITMO University (St. Petersburg) is detailed, its efficiency is assessed.
\end{abstract}

Keywords: Pre-university training, design skills, 3D modeling. 


\section{Introduction}

Pre-university training is the educational component that later helps the students to cope successfully with the college curriculum; due to the diversity of approaches and methods, it can ensure the continuity of education (Medvedeva, 2012). Computer courses in 3D modeling for the school-level students are a helpful step both for those college-students-tobe who plan to work in this professional domain and for those who would receive training in engineering, since these courses encourage the development of spatial ability (Šafhalter,Glodež,Aberšek,\&Bakračevič Vukman, 2014) and lay the groundwork for a wide range of professional skills (Lokalov,Makhlai,Klimov,\&Sopronenko, 2015). Design skills hold a place of prominence within this range.

Currently, special emphasis is placed on introducing the technical design skills both at the secondary - (Strimel, 2012) and high-school level (Mourtos, 2012). However, the introduction of design skills in teaching 3D modeling presents its own challenges. Unlike designing the models of material objects or technical devices, the designing of virtual 3D models doesn't stimulate the student to lay special emphasis on the design stage, since a virtual object is much easier to make or correct than a material one. Resorting to the computational power of the computer, the students tend to replace the stage of planning and of searching for the solution for a computer modeling problem by manipulations with the tool infrastructure, and opt for the trial and error approach in looking for the solution. This tack can turn into an automatic habit and, at the stage of modeling more complex objects, lead to faults and errors in the final product, including the fatal ones. Badly designed 3D models require more rendering time, and their use in real time (a game or a virtual environment) can be hampered. An attempt should be made to resolve this issue at the preuniversity level of training.

\section{Methods}

\subsection{Theoretical Framework}

To avoid early habitualization of the students' faulty approaches to handling the 3D modeling tasks, it seems worthwhile to control the formation of the design skills beginning with the stage of introducing the students to the 3D modeling tool infrastructures (elementary stage) and up to the stage where the students are qualified enough to handle professionally-oriented projects (professional stage). To define the methods that ensure an efficient transition from the elementary stage to the professional one, let's compare the patterns the students use at both stages. We believe that the most appropriate approach is to use Galperin's theory of systematic formation of mental actions $(1989,1992)$ that reconciles Vygotsky's concept of the zone of proximal development with teaching practices (Haenen, 
2001). Galperin suggests that a special stage, the so-called orienting basis of action (OBA), should be distinguished within the pattern of an action directed at solving the problem. Both the quality and the successful outcome of the action fully depend on this stage. The process of OBA includes:

- assessing the image of the situation and pinpointing the components crucial for solving the problem; comparing the components with the previous experience;

- searching for the solution (with the pinpointed components taken into the account), planning (determining the operational structure of the action and the tools);

- adjusting the action throughout the process.

It's obvious that OBA represents the psychological pattern that is responsible for the development of the design skills. In consistence with the well-known notion of psychological development as a process of differentiation (Witkin, 1962), it can be surmised that in moving from the elementary stage of studying the $3 \mathrm{D}$ modeling to the professional stage in OBA, the abovementioned components of OBA should be transformed into more complex structures, i. e.:

- task setting and analyzing;

- creative search for a solution, elaboration of the project;

- implementation and fine-tuning of the project.

The moment when all the listed components are introduced to the action pattern, signifies the beginning of the basic stage of developing the design skills. From that point on, throughout the transition to the professional stage of development, the structural complexity of OBA will keep increasing. Consequently, the three abovementioned stages can be distinguished within the process of developing the design skills for 3D modeling. At each of the stages, specific goals should be set that would encourage the students to develop the design skills (OBA structures), and to improve the intellectual abilities related to those skills.

\subsection{Skill Development: Stages}

The elementary stage should not be limited to the formal introduction to the design process (the necessary prerequisites for full-scale designing haven't been shaped yet); it should rather empower the students through diversifying the elements of their experience. This would allow them later to recognize these elements as the significant components of the OBA structure at the design stage. That's why the tasks assigned to the students should be both fairly simple (several instrumental operations) and diversified. In the beginning, the students should be introduced to a wide range of interfaces of the 3D modeling programs 
and to various types of shaping used therein. As a rule, it's fairly easy to introduce these types, linking them to the students' previous experience, using such metaphors as molding, sketching, modular construction. The students should be made to understand the special features of working with such virtual "matter" as polygonal mesh. Through solving simple and maximally diversified problems, the students would definitely improve their creativity that is essential for designing $3 \mathrm{D}$ objects.

At the basic stage it's essential to make a quick move to the tasks that would encourage the students to incorporate the design process into the overall process of model building. This can be achieved either if the assignment includes additional requirements for the structure, functions or technology of the design model (e. g. to make a model from the given primitive elements with the minimal-size polygonal mesh) or if the assignment implies designing a model of a complex shape. Both approaches encourage the students to look for various solutions and to document their versions through making sketches. To be able to select the preferable version, they would first have to come up with the assessment criteria (e. g. the minimal number of operations) and then to use these criteria to analyze their results - the above leads to improving the convergent thinking abilities. As the result, the design stage would be introduced to the OBA structure, including the search for the optimal polygonal structure of the $3 \mathrm{D}$ model, that would be perceived by the students as a significant component of their project.

As for the practical assignments at the professional stage, they should be very similar to the professionally-oriented tasks. In order to cope with them, the students should master the existing technologies of designing the 3D models, as well as the requirements for these models determined by the functional properties of the final product (animation, game, virtual space, a 3D-printing model). This leads to the further differentiation of the students' OBA structure that has been shaped at the previous stage; new significant components are introduced therein. For instance, restricted polygonal mesh parameters might serve as a significant component in designing a computer game character, since the ability to control the character in real time depends on it. In the absence of the abovementioned OBA differentiation, there's a high probability that the resulting model would require a considerable amount of fine-tuning, or, possibly, would prove completely dysfunctional. Unlike the previous stages, the tasks set at the professional stage should encourage the students to look for a compromise under the contradictory conditions, e. g. in a situation when the box technological solutions speed up the process, but impair the quality of the final product. That means that, at the professional stage, yet another intellectual ability that is crucial for design skills, the ability to make evaluative judgments, is being developed. 


\subsection{Implementation}

As a case study for the implementation of the suggested approach we would like to detail the system of developing the design skills at a pre-university educational establishment Schoolchildren's Computer Center (SCC) of ITMO University (St. Petersburg). The students begin their studies of 3D graphics at the age of 11-12, at the elementary course Introduction to Computer Graphics (BV Course). At this stage, the students are introduced both to the $3 \mathrm{D}$ graphics and to the various 2D-graphics applications (designer and animation software). This helps them with basic orientation in computer graphics as a whole, as well as with making informed decisions as to their subsequent studies within the SCC computer course system. Besides, while studying the 2D designer programs, the students can design their own textures, backgrounds and sketches for 3D models. BV is a 96 hour course, with 18 hours dedicated to studying 3D graphics. Using various shaping devices, the students learn to make simple 3D models in Sculptris (3D) and Google SketchUp. The reason for choosing the abovementioned programs is that they offer a wide range of shaping technologies. The assignments feature various favorite children's characters and their respective environments.

The basic stage of developing design skills within the SCC curriculum begins with the Basic 3D Modeling course (M Course). The main goal of M Course (96 hours), intended for the students 11-12 years old, is to train them to design 3D objects and scenes - their shapes can be acquired with the help of a set of tools offered by 3DS Max program. Designing is an essential component of creating 3D scenes and complex objects. The Figure1 shows a student's project, with detailed shaping operations, as well as the resulting model.
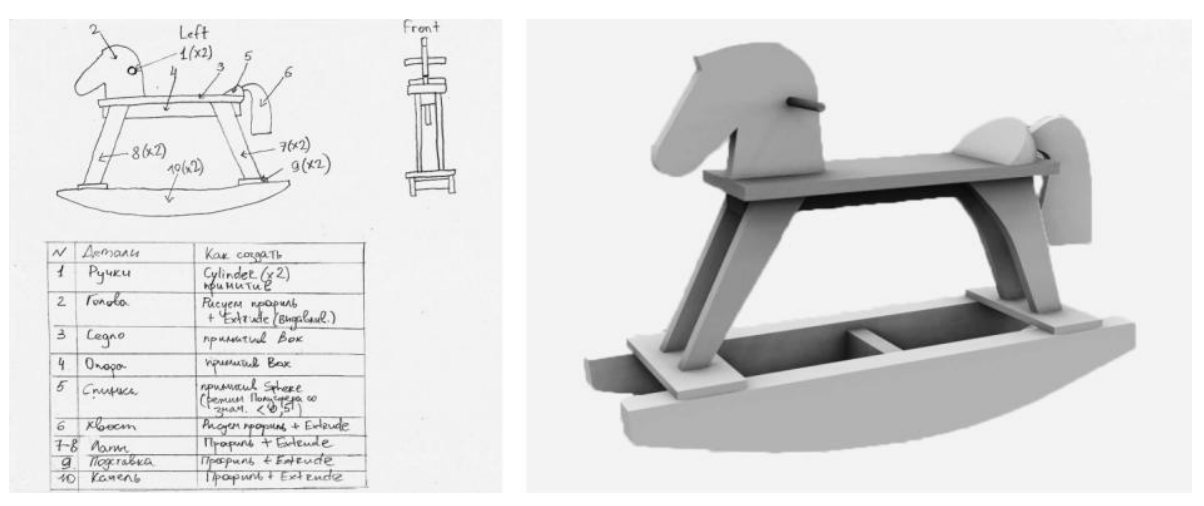

Figure 1. Rocking Horse, a sample of a project and a model (M Course).

Once the basic M Course of the SCC system is completed, the students are offered a choice of specialized professionally-oriented courses in 3D graphics: Game Design (GM Course), 
Animation Studio (SA Course) and Virtual Reality Design (VR Course). The quality of design at this stage is determined not only by the students' skills in creating optimal models, but also by their ability to take the functional properties of the model into account. Thus, in VR Course the project solutions are related both to the implementation sphere of the virtual reality application for which the model is designed (education, tourism, architecture etc.) and to the types of the virtual reality gear used therein. For instance, the use of the mobile devices gear with low productivity, sets considerable restrictions on the complexity of the model.

\section{Results and Discussion}

Since specific goals are set at each step of developing design skills, the criteria for assessing the results of the intermediary stages are different too. At the first stage, it's essential to assess the creativity (e. g. the originality of the product and the technological solution). At the second stage, the creativity criterion should be supplemented by the criterion of the project's optimality (optimality of geometry and technology). And, finally, on the third stage, the criterion of the functionality of the resulting model should be added to the two abovementioned ones.

To facilitate the expert assessment, we matched each criterion with a nominative scale, expressed both through the verbal indication of the presence of a certain quality, and through ranking them on the scale of 1 to 10 . The assessment of the method's efficiency was conducted through the comparison of the works and projects of two groups of students, A and B. The students of A Group went through all the stages of design skills development in SCC. Group B included the other students, those who went directly to the M Course or to one of the higher-level courses, since they already possessed the required 3D modeling skills they had obtained outside SCC. The number of such students is fairly high (ca. 40 percent). Table 1 shows the students' average results achieved in the academic year 2015-16, assessed by three parameters. The total number of assessed students is 97 .

Table 1. Mean Value of the Assessment Criteria of Design Skills Development.

\begin{tabular}{|c|c|c|c|c|}
\hline \multirow{2}{*}{ Groups } & \multirow{2}{*}{ Parameters } & \multicolumn{3}{|c|}{ Stages } \\
\cline { 3 - 5 } & & Elementary & Basic & Professional \\
\hline \multirow{3}{*}{ A } & creativity & 6,33 & 7,52 & 7,92 \\
\cline { 2 - 5 } & optimality & - & 8,03 & 9,19 \\
\cline { 2 - 5 } & functionality & - & - & 9,57 \\
\hline \multirow{3}{*}{ B } & creativity & - & 7,60 & 7,75 \\
\cline { 2 - 5 } & optimality & - & 5,71 & 7,10 \\
\cline { 2 - 5 } & functionality & - & - & 7,22 \\
\hline
\end{tabular}

The maximal standard deviation didn't exceed 0,91. Table 1 shows significant differences between the A and B Groups as far as optimality and functionality criteria go; the above 
seems to testify to the efficiency of the suggested approach to the development of design skills.

\section{Conclusions}

The article suggests that the approach to the development of design skills can be based on the process of gradual differentiation of the students' OBA structure in dealing with the practical tasks.

We believe that this approach is highly workable, even though it can benefit from more detailed research, in order to better adapt it to the needs of a specific educational process. For instance, it's essential to find the most efficient, student-friendly way to describe the project of a 3D model, since the traditional graphical engineering approaches are not only way too challenging for secondary school students, but also unusable for describing the stages of shaping. Related research is currently being conducted.

We plan to use the suggested approach to the development of design skills in the other computer technologies courses for the pre-university students.

\section{References}

Galperin, P.I. (1989) Organization of mental activity and effectiveness of learning. Soviet Psychology, 27 (3), 65-82.

Galperin, P.I. (1992). Stage-by-stage formation as a method of psychological investigation. Journal of Russian \& East European Psychology, 30(4), 60-80.

Haenen J. (2001) Outlining the teaching-learning process: Piotr Gal'perin's contribution. Learning and Instruction 11, 157-170.

Lokalov V.A., Makhlai D.O., Klimov I.V., \& Sopronenko L.P. (2015). Students' Vocational Skills Developing Through 3D-Modeling of Classic Still Lives. Proceedings from EVA 2015: Electronic Imaging \& the Visual Arts. St Petersburg, Russia, 188-191.

Medvedeva, D.O. (2012). Pre-university training in the system of lifelong education to provide continuity of transition from secondary school to University. Lifelong learning: continuous education for sustainable development, 1, 312. Retrieved from http://cyberleninka.ru/article/n/pre-university-training-in-the-system-of-lifelongeducation-to-provide-continuity-of-transition-from-secondary-school-to-university.

Mourtos, N. J. (2012). Defining, Teaching, and Assessing Engineering Design Skills. International Journal of Quality Assurance in Engineering and Technology Education, 2(1), 14-30.

Šafhalter A., Glodež, S., Aberšek, B., \& Bakračevič Vukman, K. (2014). Developing spatial ability using 3D modeling in lower secondary school. Philosophy of Mind and Cognitive Modelling in Education, 61, 113-120. 
Strimel,G. (2012). Engineering by Design ${ }^{\mathrm{TM}}$ : Preparing Students For the 21st Century. Proceedings from PATT 26: Conference; Technology Education in the 21st Century. Stockholm, Sweden.

Witkin, H. A. (1962). Psychological differentiation: studies of development. New York: Wiley. 